\title{
Effect of different parameters on lateral- torsional buckling behavior of I-girders with circular corrugated webs
}

\author{
Sh. M. Swelem, A. Sh. Fahmy and N. F. El Sherif*
}

\section{*Correspondence:}

eng-nermeen.fouad@alexu. edu.eg

Department of Structural Engineering, Faculty

of Engineering, Alexandria

University, Alexandria, Egypt

\begin{abstract}
I-girders with circular corrugated webs are considered as a new fabrication technology. The corrugation of the web considerably increases the stiffness of the cross-section to resist shear forces and also increases the out-of-plane stiffness. However, investigations on the lateral-torsional buckling behavior of the circular corrugated web girders are still scarce. Therefore, the present study focuses on the lateral-torsional buckling performance of these types of girders. A numerical study is performed in order to simulate the inelastic lateral-torsional buckling behavior of the I-girders with the circular corrugated web using ABAQUS software. A parametric study is carried out taking into account both linear and non-linear buckling analyses, to investigate the effect of different geometrical parameters on the inelastic lateral-torsional buckling behavior using three different corrugated web profiles. The results indicate that increasing the corrugation depth, flange width, flange thickness, and web height increases the moment capacity of these girders. The results of the parametric study show that the moment capacity of the I-girders with the circular corrugated web is higher than those with flat web girders.
\end{abstract}

Keywords: Circular corrugated web girders, Finite element analysis, Lateral-torsional buckling, Moment capacity, Numerical analysis, Parametric study

\section{Introduction}

I-girder with the corrugated web is an alternative solution to transverse stiffeners to increase out-of-plane stiffness and fatigue resistance of steel girders. Additionally, reducing selfweight of the girder and fabrication cost. Therefore corrugated web girders have had widespread usage in steel structures since the 1990s. In order to use them safely, designed models subjected to different straining actions should be provided for these innovative girders. The earliest investigation of the lateral-torsional buckling behavior of the corrugated web girders was by Lindner [1]. He proposed empirical formulas for the warping constant of the I-girders with the corrugated web based on experimental studies. Subsequently, Sayed-Ahmed [2] used an equivalent web thickness $\left(t_{\text {eq }}\right)$ to determine the corrugated web girders strength. Ibrahim [3] studied the lateral-torsional buckling strength of girders consisting of rectangular tubular flange accompanied with the corrugated web. Chan et al. [4] investigated the

(c) The Author(s) 2022. Open Access This article is licensed under a Creative Commons Attribution 4.0 International License, which permits use, sharing, adaptation, distribution and reproduction in any medium or format, as long as you give appropriate credit to the original author(s) and the source, provide a link to the Creative Commons licence, and indicate if changes were made. The images or other third party material in this article are included in the article's Creative Commons licence, unless indicated otherwise in a credit line to the material. If material is not included in the article's Creative Commons licence and your intended use is not permitted by statutory regulation or exceeds the permitted use, you will need to obtain permission directly from the copyright holder. To view a copy of this licence, visit http:// creativecommons.org/licenses/by/4.0/. The Creative Commons Public Domain Dedication waiver (http://creativecommons.org/publi cdomain/zero/1.0/) applies to the data made available in this article, unless otherwise stated in a credit line to the data. 
beam with the corrugated web in both directions vertically and horizontally. He concluded that the strength of girders with the vertical corrugated web was higher than that of the girders with the horizontal corrugated web. Moon et al. [5] proposed an expression for the warping constant of the corrugated web girders based on the force method with ignoring the web contribution due to its accordion effect. Nguyen et al. [6] followed the same approach as Moon et al. except for the contribution of the corrugated web which was considered to be fully active and taken into account. Zhang et al. [7] suggested that the calculations of the corrugated web were similar to the flat web except for the eccentricity of the web. A modified torsional and warping constant of the corrugated web girders is introduced by [8-10]. In addition, the elastic lateral-torsional behavior of the corrugated web girders was investigated numerically according to $[11,12]$. While the inelastic lateral-torsional buckling performance was investigated experimentally by [13-15] and numerically using nonlinear finite element analyses by [16-20]. However, not many researches studied the lateral-torsional buckling behavior of the circular corrugated web girder.

\section{Methodology}

The aim of this paper is to study the lateral-torsional buckling behavior of the I-girders with a circular corrugated web. In addition, studying the effect of various geometrical parameters on the moment capacity of these girders. A comparison in the moment capacity between beams with corrugated web and those with the flat web is conducted. In this paper, a numerical study is carried out to simulate the beam model with a circular corrugated web using ABAQUS software. Then the finite element model will be validated based on the previous experimental tests by Elkawas et al. [21]. A parametric study is performed to investigate the effect of geometrical parameters on the lateral-torsional buckling behavior. The moment capacity of the I-girders with the corrugated web is compared with that of the flat web girders in order to quantify the increase of moment capacity of corrugated web girders and evaluate the benefit of using these girders.

\section{Finite element modeling}

The finite element model is performed using ABAQUS software version 2019 [22] in order to simulate the lateral-torsional buckling behavior of the I-girder with circular corrugated web and estimate its moment capacity. The variables of the I-girder are shown in Fig. 1, where $S$ is the wavelength of the corrugated web, $q$ is the wave width, $h_{r}$ is the depth of the corrugation, $H$ is the girder depth, $h_{w}$ is the corrugated web height, $t_{w}$ is web thickness, $b_{f}$ is the flange width, and tf is the flange thickness. The $X, Y$, and $Z$ axes shown in this figure are the global axes of the girders.

\section{Elements type and mesh configuration}

ABAQUS has an expansive library of elements suitable for various types of analysis. Shell elements are a good choice to model structures that has small thicknesses in comparison with their other dimensions. Two shell element types are used, Linear (S4R) and Quadratic (S8R) shell elements, to investigate the suitable element type for this analysis, convergence study is performed for I-girder with circular corrugated web model, with dimensions according to Table 1 . The global size of the mesh varies from $30 \mathrm{~mm}$ to $8 \mathrm{~mm}$ to get the finite element analysis accuracy and achieve time-saving. Although (S8R) elements converge earlier than S4R elements, they are more complex and require 


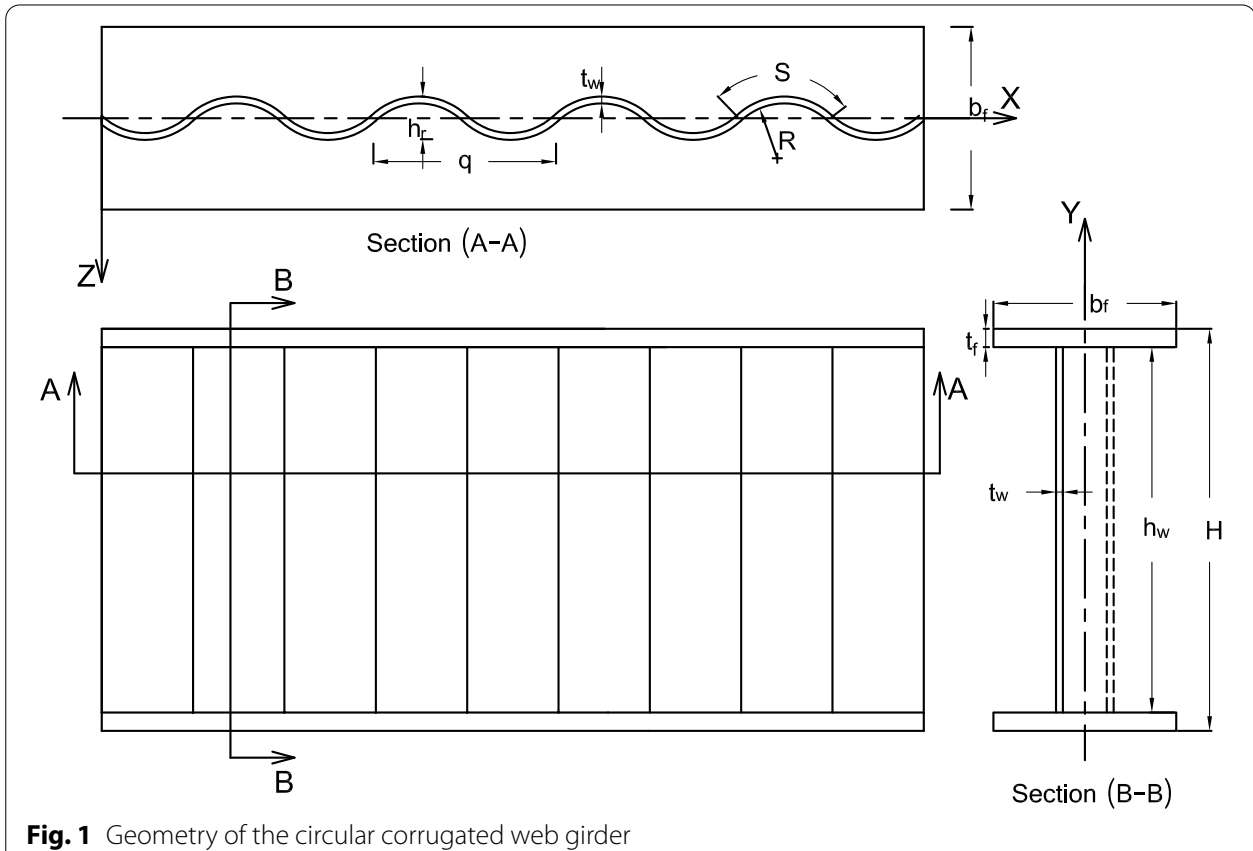

Table 1 Dimensions of the used finite element model in the convergence studies

\begin{tabular}{lllllll}
\hline $\mathrm{L}(\mathbf{m m})$ & $\boldsymbol{b}_{\boldsymbol{f}}(\mathbf{m m})$ & $\boldsymbol{t}_{\boldsymbol{f}}(\mathbf{m m})$ & $\boldsymbol{H}(\mathbf{m m})$ & $\boldsymbol{t}_{w}(\mathbf{m m})$ & $\boldsymbol{h}_{\boldsymbol{r}}(\mathbf{m m})$ & $\boldsymbol{q}(\mathbf{m m})$ \\
\hline 4500 & 120 & 10 & 240 & 3.75 & 50 & 150 \\
\hline
\end{tabular}

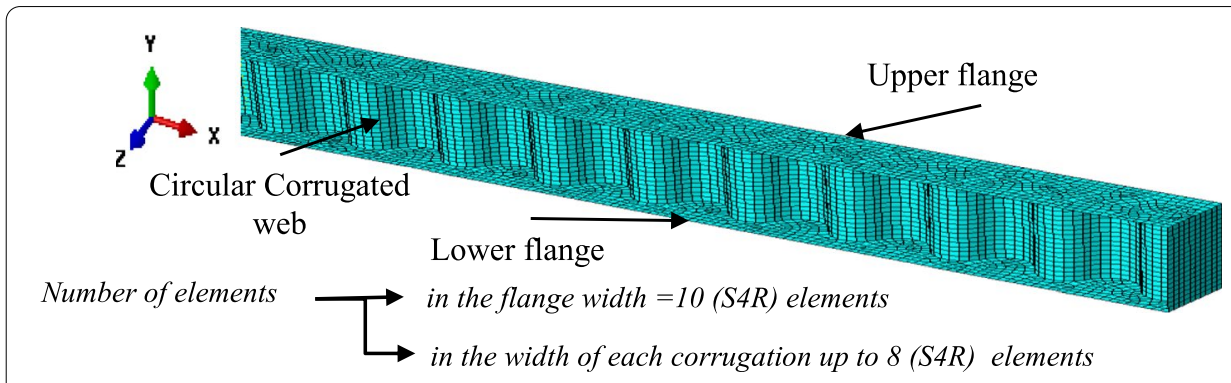

Fig. 2 Finite element mesh of I-girder with circular corrugated

more computations per element. The convergence results of S8R and S4R elements are identical at finer mesh. Therefore, the S4R elements are chosen to simulate the finite element model. The mesh of the models is formed of ten elements per flange width and more than eight elements along the wavelength of the circular corrugation in the web as shown in Fig. 2. The results from the convergence study performed for the nonlinear buckling analysis model are presented in Fig. 3, where the horizontal axis denotes the numbers of element and the vertical axis refers to the ultimate bending moment $\left(M_{\mathrm{ul}, \mathrm{FE}}\right)$.

\section{Boundary conditions and loading}

Each girder is loaded by two concentrated point loads acting at one third and two thirds of the upper flange span at the center line of the flange, resulting in zero shear and pure 


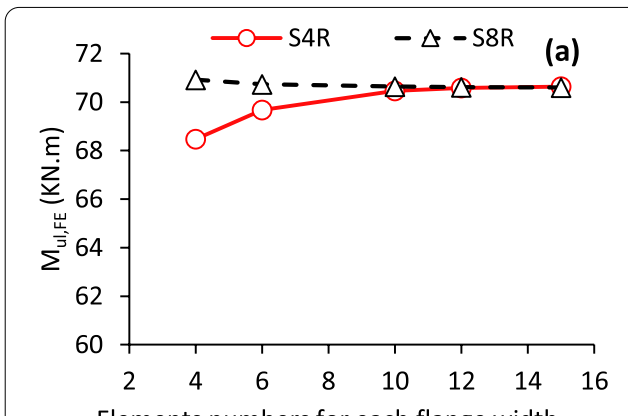

Fig. 3 Convergence analysis results of the current models

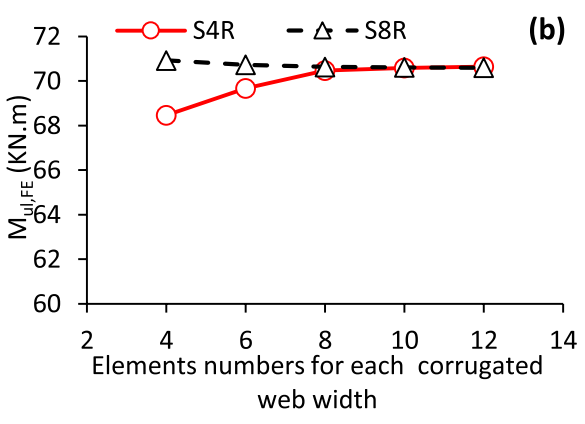

moment at the middle third of the span as shown in Fig. 4. Boundary conditions of all models are simply supported at the nodes of the bottom flanges where the end stiffeners are located. Figure 5 shows the loading and boundary conditions. Line 1 is hinged support, where the lateral displacement is prevented in the $z$-direction $\left(u_{z}=0.0\right)$, the longitudinal movement is restrained in the $x$-axis $\left(u_{x}=0.0\right)$ and the vertical displacement is prevented $\left(u_{y}=0.0\right)$. Line 2 is roller support, where the displacement in the $z$-and $y$-directions are restrained $\left(u_{z}=0.0, u_{y}=0.0\right)$.

\section{Material properties}

In the non-linear (RIKS) analysis, the material is defined as shown in Fig. 6. The trilinear stress-strain curve relationship is used to study the material non-linearity and large
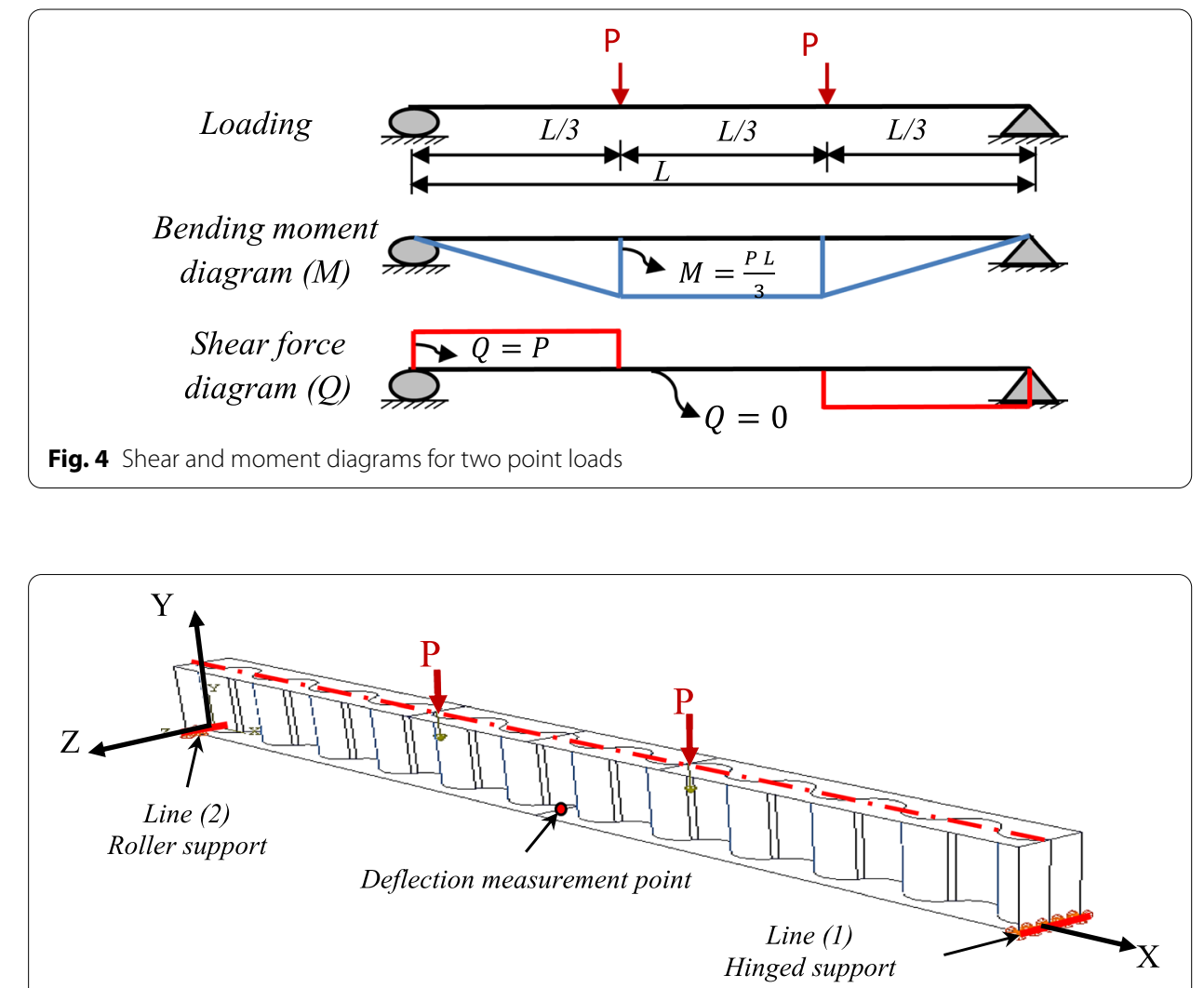

Fig. 5 Loading and boundary condition of the finite element analysis 


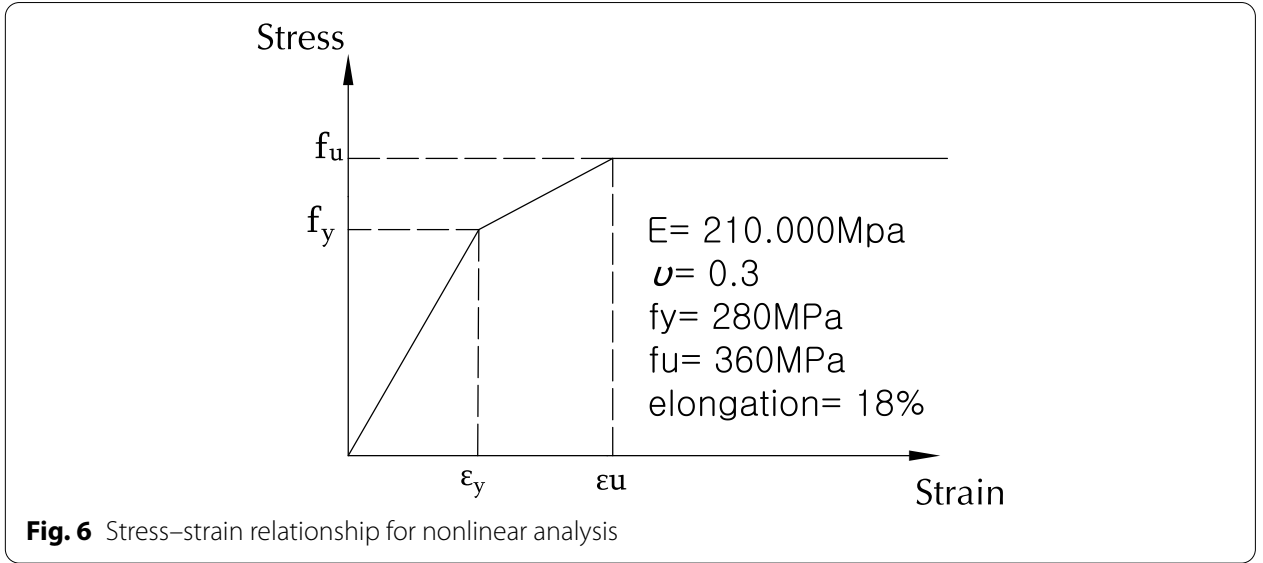

deformation as used by Moon et al. [5] to simulate the material behavior, which follows the Von-Mises yield stress criterion with isotropic hardening rule. The modulus of elasticity $(E)$ equals $210.000 \mathrm{MPa}$, Poisson ratio $(v)$ is 0.3 , the yield stress $\left(f_{y}\right)$ is taken as 280 $\mathrm{MPa}$, the ultimate stress $\left(f_{u}\right)$ is $360 \mathrm{MPa}$, and the elongation is $18 \%$. These properties are adopted based on the properties of (S280GD) according to European standards.

\section{Applied analysis and geometric imperfection}

Two analysis steps are performed in order to simulate the inelastic lateral-torsional buckling behavior of the I-girders with circular corrugated webs. In the first instance, the *BUCKLE procedure in ABAQUS simulates the elastic buckling analysis to estimate the critical buckling loads of the model and the structure deforms (Eigenmode). For this study, three Eigenvalues for each girder are extracted. The worst case of the buckling load is considered in the design, which is the lowest Eigenvalue. The next step is a geometrical and material nonlinear analysis by applying the modified RIKS method. The applied equivalent geometric imperfection is taken as $L / 1000$ similar to the previous investigations by $[5,18]$, where $L$ is the span of the girder. This is the same value recommended by the EC3 [23] where the initial geometric imperfections and the residual stresses are represented by equivalent geometric imperfections with a magnitude of $L / 1000$ in the case of global buckling.

\section{Verification of the finite element model}

The finite element model is verified based on the previous experimental test results of Elkawas et al. [21] using three simply-supported specimens G-400-80, G-400-100, and G-300-80 with a span of $3000 \mathrm{~mm}$. The web consists of three parts, corrugated web in the middle part with length of $1800 \mathrm{~mm}$ and $3 \mathrm{~mm}$ thickness. The left and right parts are flat webs with $8 \mathrm{~mm}$ thickness. The flange thickness is taken as $16 \mathrm{~mm}$. The flange width and web height are considered as a variable. Where, specimen G-400-80 is considered as the control girder with a flange width $80 \mathrm{~mm}$ and a web height of $400 \mathrm{~mm}$. The flange width varies to $100 \mathrm{~mm}$ in the second specimen G-400-100, while the web height in the third specimen G-300-80 is changed to $300 \mathrm{~mm}$. Each girder is tested under two point loads that act on the upper flange to obtain a pure bending moment in the middle part of the girder. The corrugation profile dimensions of the girders are given in Fig. 7. 


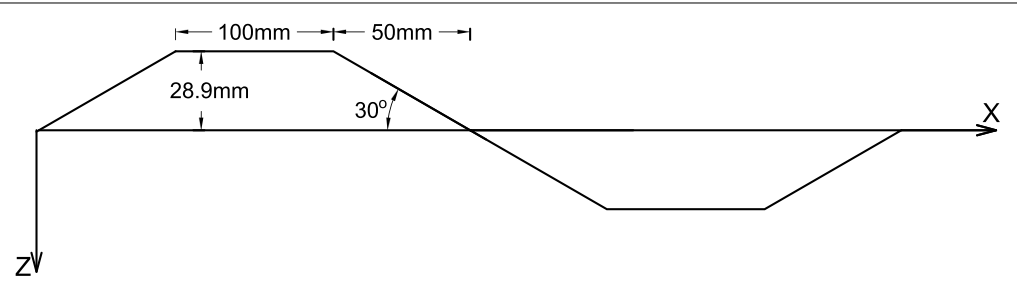

Fig. 7 Dimensions of the corrugated web profile for test specimens

Table 2 Comparison between finite element and experimental ultimate moments

\begin{tabular}{lllc}
\hline Girder & $\begin{array}{l}\boldsymbol{M}_{\text {ul, EX }} \\
(\text { KN.m) }\end{array}$ & $\begin{array}{l}\boldsymbol{M}_{\text {ul,FE }} \\
(\text { KN.m) }\end{array}$ & $\left(\frac{M_{\text {ulFE }}}{M_{\text {ul.EX }}}\right)$ \\
\hline G-400-80 & 135 & 135.747 & 1.01 \\
G-400-100 & 183.6 & 185.262 & 1.01 \\
G-300-80 & 124.4 & 119.186 & 0.96 \\
\hline
\end{tabular}

The yield stress $\left(f_{y}\right)$ is taken 295,287 and $304 \mathrm{MPa}$ for flanges, flat web, and corrugated web, respectively. The stress-strain relationship is simulated an elastic perfectly plastic relationship. The Poisson's ratio $(v)$ is taken as 0.3 . In this verification, the girders are simulated by using ABAQUS software version 2019. The element type used in the numerical analysis is four-node shell elements (S4R) which has linear base function and reduced integration. Also, the mesh is taken similar to the applied mesh by Elkawas et al. [21]. A linear buckling analysis (Eigenvalue buckling analysis) is performed to determine the critical buckling moment. Nonlinear analysis is carried out using the modified RIKS method to simulate the geometrical and material nonlinearities taking into account the initial geometrical imperfection of $L / 1000$, where $L$ is the girder span. Table 2 shows the ratio of the finite element ultimate moment to the experimental ultimate moment $\left(\frac{M_{\mathrm{ul} . \mathrm{FE}}}{M_{\mathrm{ul} \text {.EX }}}\right)$ for the girders. The result of the numerical analysis and those obtained from the experimental test show good agreement. Figure 8 shows the relationship between the bending moment versus mid-span vertical displacement that is obtained from the finite element analysis and experimental tests.

\section{Parametric study}

Based on the finite element model verification results of the previous section, the finite element model can be used safely to simulate the behavior of the lateral-torsional buckling of girders with circular corrugated webs. A parametric study is performed taking into account the linear and non-linear buckling analyses. The aim of this parametric study is to investigate the effect of the geometrical parameters on the lateral-torsional buckling performance of circular corrugated web girders. Three corrugated web profiles are chosen as follows: the width of the corrugation $(q)$ is considered as $180 \mathrm{~mm}, 150 \mathrm{~mm}$, and $100 \mathrm{~mm}$ for the CW-180, CW-150, and CW-100 steel girders models, respectively as presented in Table 3. The corrugation depth $\left(h_{r}\right)$ is taken $50 \mathrm{~mm}$ for models CW-150 and CW-180 and 20mm for model CW-100 steel girder. Figure 9 shows the geometric notations of the corrugated web. An equivalent girder with a flat web (FW) is proposed to be 


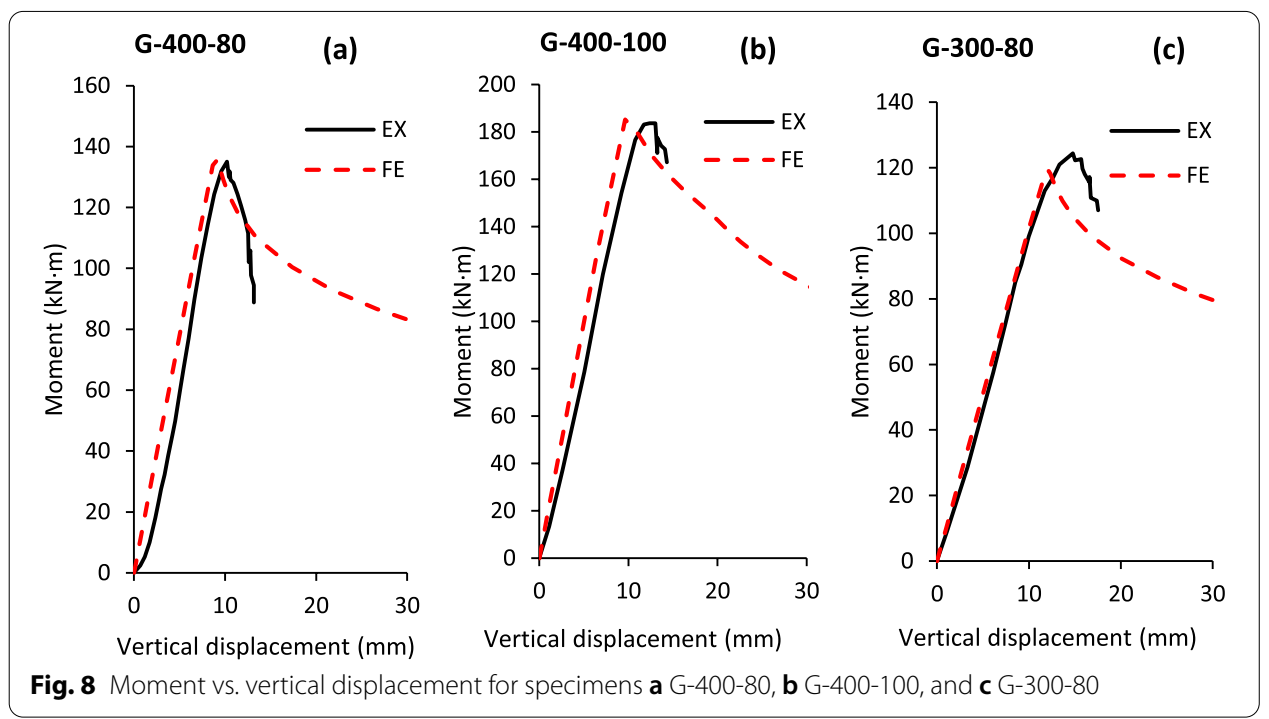

Table 3 Dimensions of the geometrical profiles of circular corrugated web

\begin{tabular}{llll}
\hline Girder & $\boldsymbol{R}(\mathbf{m m})$ & $\boldsymbol{q}(\mathbf{m m})$ & $\boldsymbol{h}_{\boldsymbol{r}}(\mathbf{m m})$ \\
\hline CW-100 & 28.66 & 100 & 20 \\
CW-150 & 40 & 150 & 50 \\
CW-180 & 40 & 180 & 50 \\
\hline
\end{tabular}

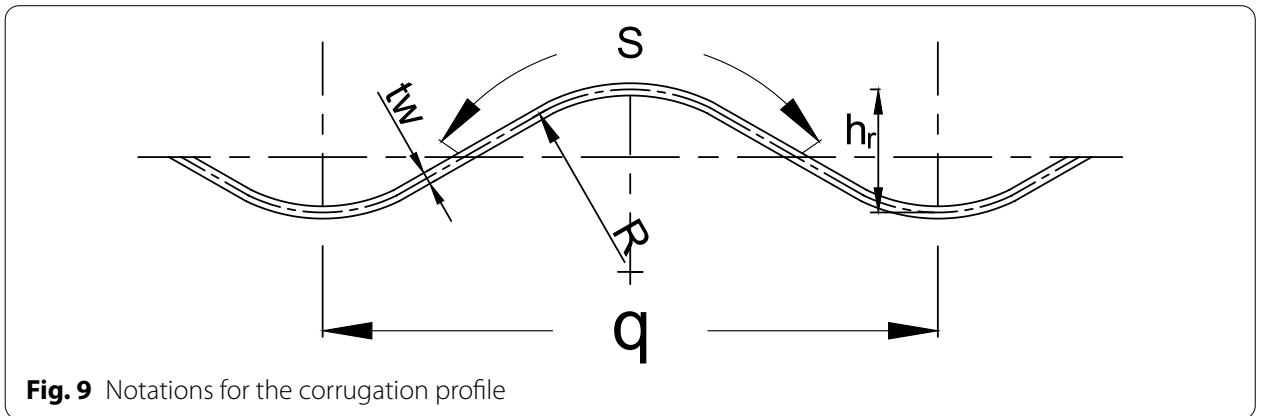

a corresponding weight of the corrugated web girder $(\mathrm{CW})$. The thickness of the flat web $\left(t_{\text {equ }}\right)$ is determined as:

$$
t_{\mathrm{equ}}=t_{w}\left(\frac{S}{q / 2}\right)
$$

where $t_{\text {equ }}$ is the web thickness of the I-girder with flat web, $t_{w}$ is the thickness of the web of the I-girder with circular corrugated web, $S$ is the wave length for one corrugation, $(q / 2)$ is the projected length of one corrugation, and $R$ is the radius of the corrugated web. 
In this study, only girders with unbraced length $\left(L_{b}\right)$ in the range of $\left(L_{P}<L_{b} \leq L_{r}\right)$ according to Egyptian code (LRFD) [24] are considered when investigating the inelastic behavior of the lateral-torsional buckling where $L_{P}$ is limit for laterally unbraced length for full plastic bending capacity and $\left(L_{r}\right)$ is limit for laterally unbraced length for inelastic lateral-torsional buckling as represented in Eqs. (2) and (3).

$$
\begin{gathered}
L_{P}=\frac{80 r_{y}}{\sqrt{F_{y f}}} \\
L_{r}=\frac{1380 A_{f}}{d F_{L}} \sqrt{\frac{1}{2}\left(1+\sqrt{1+\left(2 X F_{L}\right)^{2}}\right)} \\
F_{L}=0.6\left(F_{y f}\right) \text { and } X=\left(\frac{0.104 r_{y} d}{A_{f}}\right)^{2}
\end{gathered}
$$

where $r_{y}$ is the radius of gyration about $y$-axis, $F_{\mathrm{yf}}$ is the yield stress of the flange, $A_{F}$ is the area of the compression flange, and $d$ is the total depth of the beam. The beam dimensions are considered as $\left(\mathrm{H} \times \mathrm{b}_{\mathrm{f}} \times \mathrm{t}_{\mathrm{f}} \times \mathrm{t}_{\mathrm{w}}\right)$. The parametric study is conducted in three groups to cover the three web corrugation profiles CW-180, CW-150, and CW-100 by changing only one parameter at a time. When changing each parameter, the length of the girder that varies in the range of $\left(L_{P}<L \leq L_{r}\right)$ is the main variable. The ranges of the parameters considered in this study, other than the span (L), are:

- The flange width $\left(b_{f}\right)$ varies from $100 \mathrm{~mm}$ to $150 \mathrm{~mm}$.

- The flange thickness $\left(t_{f}\right)$ varies from $8 \mathrm{~mm}$ to $12 \mathrm{~mm}$ with an increment of $2 \mathrm{~mm}$.

- The web thickness $\left(t_{w}\right)$ varies from $2.5 \mathrm{~mm}$ to $3.75 \mathrm{~mm}$ with an increment of $0.25 \mathrm{~mm}$.

- The girder height $(H)$ varies from $240 \mathrm{~mm}$ to $360 \mathrm{~mm}$ with an increment of $30 \mathrm{~mm}$.

\section{Results and discussions}

\section{Effect of flange width}

The moment capacity increases when the flange width increases within the range of 100 to $150 \mathrm{~mm}$ as shown in Fig. 10. The moment capacities of the CW-180, CW-150, and CW-100 steel girders models are higher than those of models FW-180, FW-150, and FW-100 with an average ratio of $17.14 \%, 19.11 \%$, and $6.3 \%$, respectively.

The effect of varying the flange width $\left(b_{f}\right)$ on the moment capacity using various lengths is presented in Table 4 . The increase in the moment capacity of model CW-150 with a span of $4500 \mathrm{~mm}$ reaches $97.25 \%$ as the flange width changes from $100 \mathrm{~mm}$ to $150 \mathrm{~mm}$ as shown in Fig. 11. The moment capacity of model CW-150 is $13.6 \%$ higher than the moment capacity of model (CW-100) as shown in Fig. 12, while the moment capacity of model CW-150 is slightly higher than the moment capacity of model CW-180. This indicates the essential effect of the corrugation depth on the moment capacity of the circular corrugated web girders.

\section{Effect of flange thickness}

When the flange thickness increases in the range of $8 \mathrm{~mm}$ to $16 \mathrm{~mm}$, the moment capacity rises as presented in Fig. 13. The moment capacity of the corrugated web 


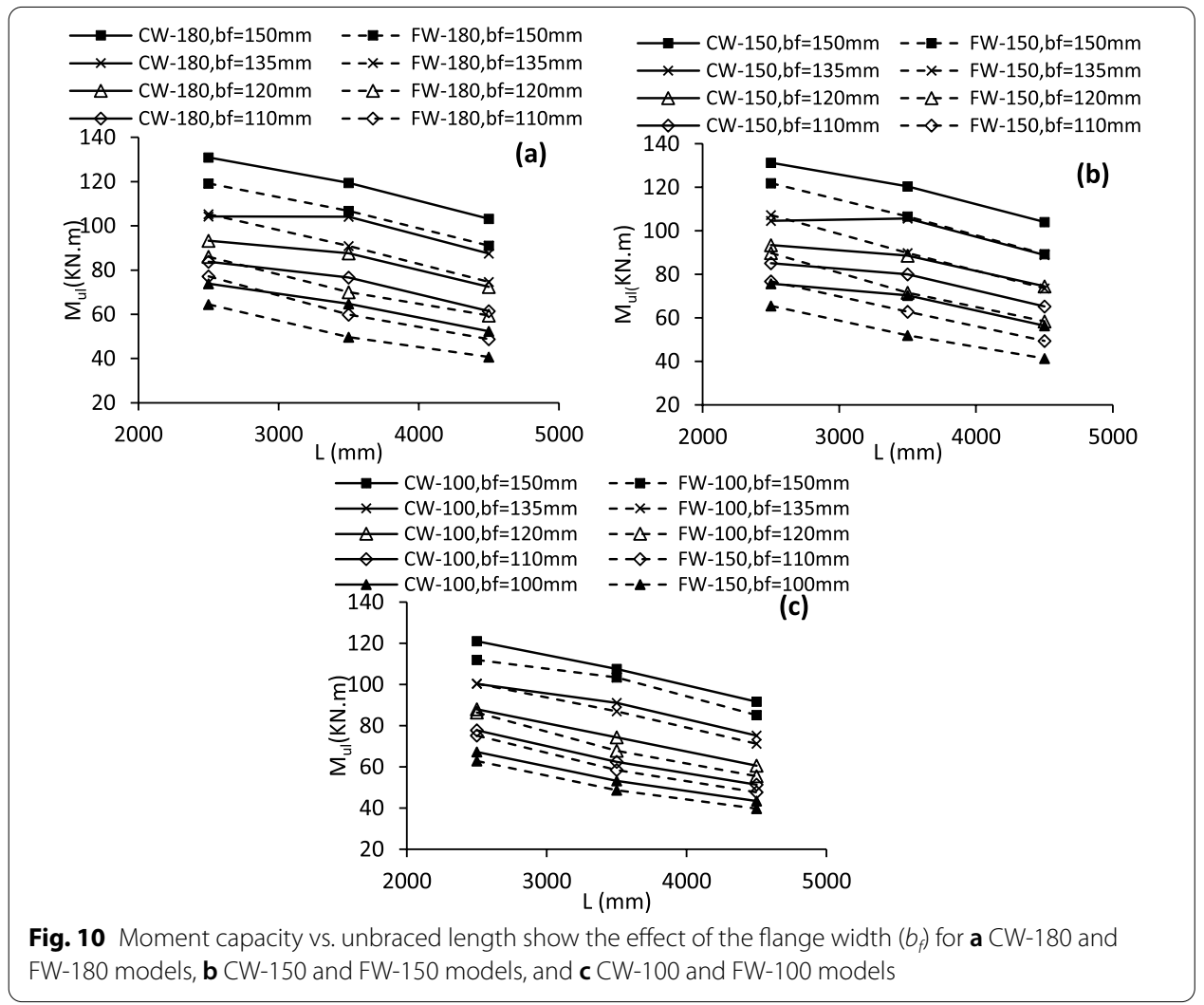

Table 4 The moment capacity using various flange widths for different model spans

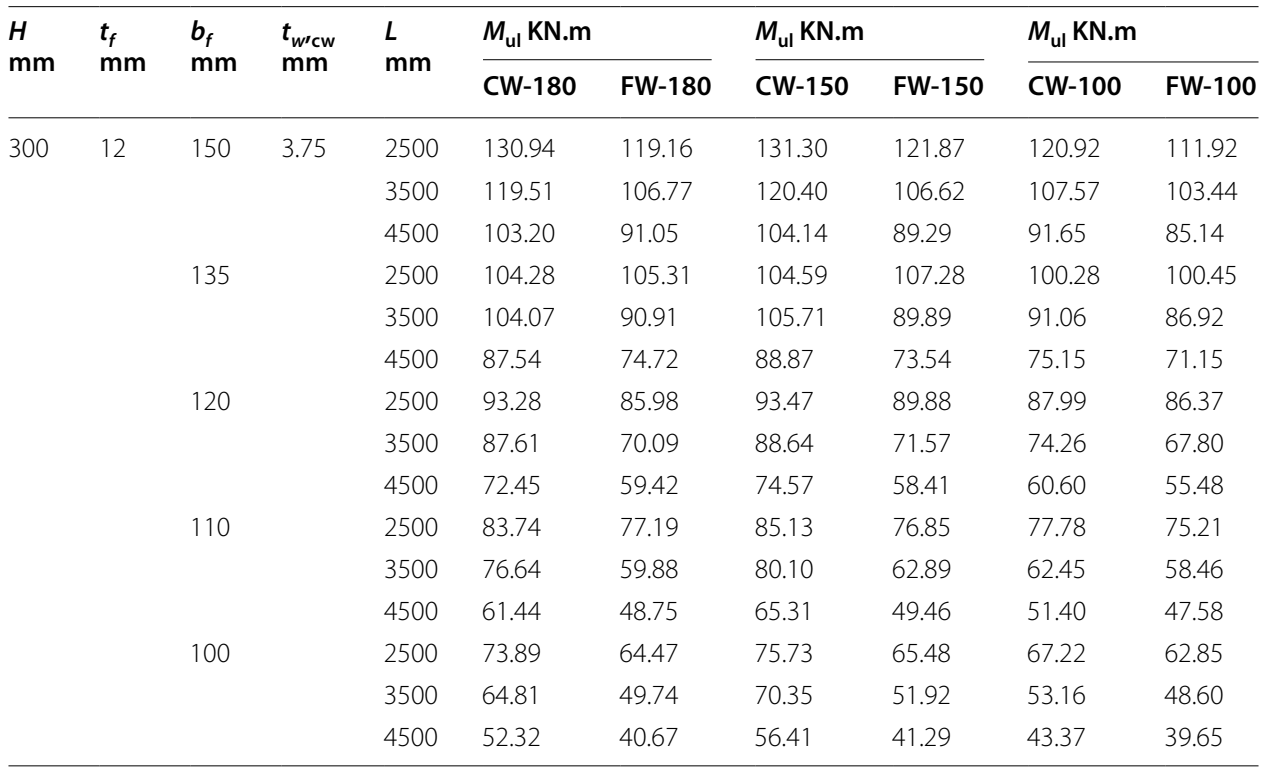

girders CW-180, CW-150, and CW-100 are higher than those of girders with flat web FW-180, FW-150, and FW-100 with an average ratio of $10.81 \%, 11.69 \%$, and $6.03 \%$, respectively. Table 5 illustrates the effect of varying the flange thickness $\left(t_{f}\right)$ on the 


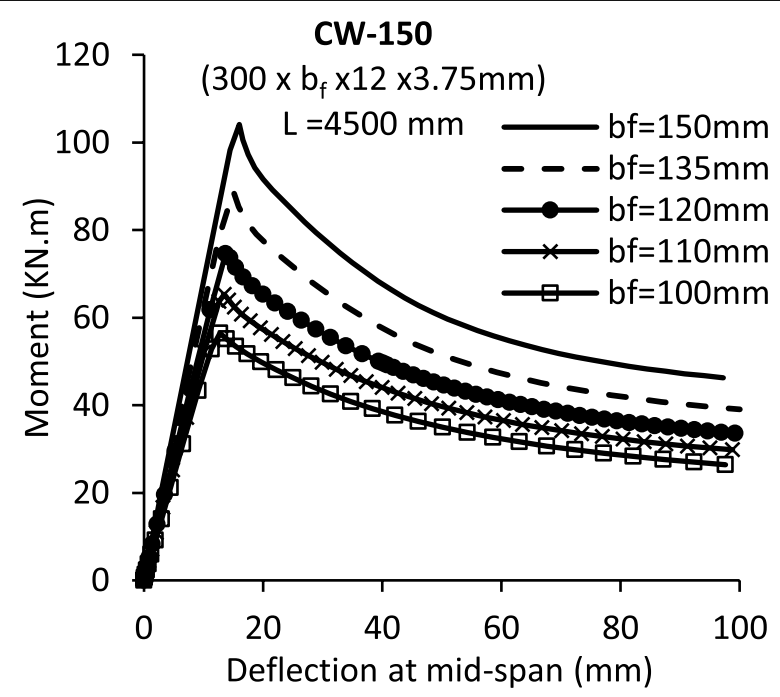

Fig. 11 Moment vs. deflection at mid-span for model CW-150 shows the effect of flange width $\left(b_{f}\right)$

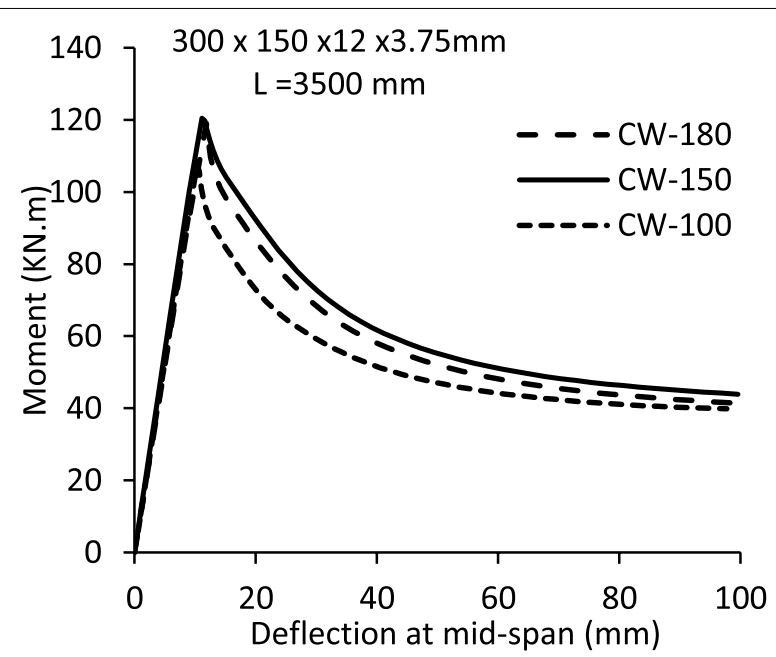

Fig. 12 Comparison between the moment capacity of CW-180, CW-150, and CW-100 models with a span of $3500 \mathrm{~mm}$

moment capacity using different lengths. The moment capacity of model CW-180 with a span of $4500 \mathrm{~mm}$ increases about $162.9 \%$ as the flange thickness increases from $8 \mathrm{~mm}$ to $16 \mathrm{~mm}$ as shown in Fig. 14. The corrugation depth has a significant effect on the moment capacity as presented in Fig. 15, where the flange thickness is taken $10 \mathrm{~mm}$ for girder with a span of $4500 \mathrm{~mm}$. The moment capacity of model CW-150 is $10.76 \%$ higher than the moment capacity of model CW-100, as the corrugation depth equals $50 \mathrm{~mm}$ and $20 \mathrm{~mm}$ for $\mathrm{CW}-150$ and CW-100, respectively, while the moment capacity values of models CW-150 and CW-180 are close to each other, as they have the same corrugation depth which is $50 \mathrm{~mm}$. 


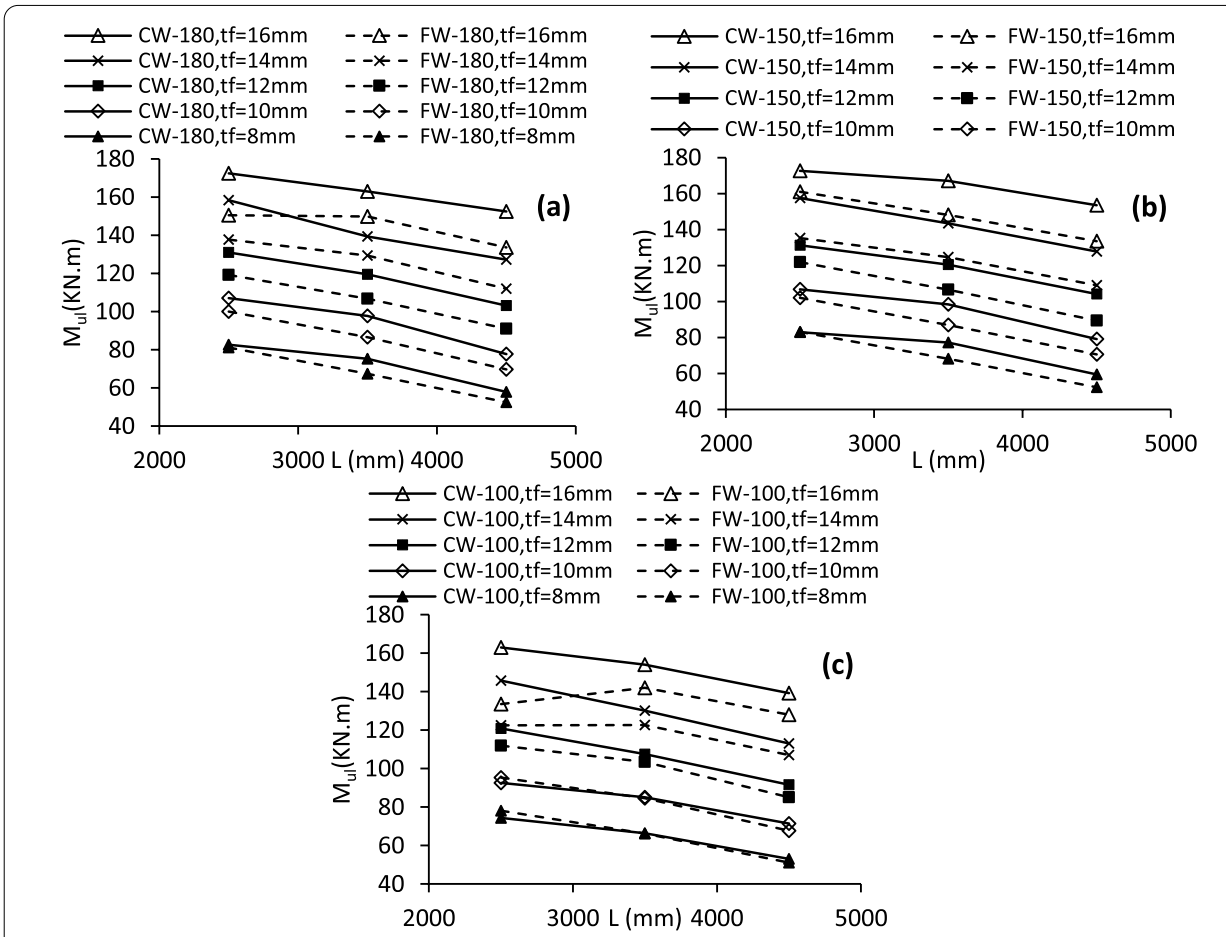

Fig. 13 Moment capacity vs. unbraced length show the effect of the flange thickness $\left(t_{f}\right)$ for a CW-180 and FW-180 models, b CW-150 and FW-150 models, and c CW-100 and FW-100 models

Table 5 The moment capacity using various flange thicknesses for different model spans

\begin{tabular}{|c|c|c|c|c|c|c|c|c|c|c|}
\hline \multirow{2}{*}{$\begin{array}{l}H \\
\mathrm{~mm}\end{array}$} & \multirow{2}{*}{$\begin{array}{l}t_{f} \\
\mathrm{~mm}\end{array}$} & \multirow{2}{*}{$\begin{array}{l}b_{f} \\
\mathrm{~mm}\end{array}$} & \multirow{2}{*}{$\begin{array}{l}t_{w^{\prime} \mathrm{cw}} \\
\mathrm{mm}\end{array}$} & \multirow{2}{*}{$\begin{array}{l}L \\
\mathrm{~mm}\end{array}$} & \multicolumn{2}{|c|}{$M_{\mathrm{ul}} \mathrm{KN} \cdot \mathrm{m}$} & \multicolumn{2}{|c|}{$M_{\mathrm{ul}} \mathrm{KN} \cdot \mathrm{m}$} & \multicolumn{2}{|l|}{$M_{\mathrm{ul}} \mathrm{KN} \cdot \mathrm{m}$} \\
\hline & & & & & CW-180 & FW-180 & CW-150 & FW-150 & $C W-100$ & FW-100 \\
\hline \multirow[t]{15}{*}{300} & \multirow[t]{3}{*}{16} & \multirow[t]{15}{*}{150} & \multirow[t]{15}{*}{3.75} & 2500 & 172.52 & 150.46 & 172.69 & 160.97 & 162.96 & 133.52 \\
\hline & & & & 3500 & 162.94 & 149.82 & 167.15 & 148.16 & 153.97 & 142.05 \\
\hline & & & & 4500 & 152.47 & 133.59 & 153.55 & 133.52 & 139.19 & 127.95 \\
\hline & \multirow[t]{3}{*}{14} & & & 2500 & 158.30 & 137.75 & 157.57 & 135.21 & 145.80 & 122.43 \\
\hline & & & & 3500 & 139.38 & 129.29 & 143.40 & 124.64 & 130.17 & 122.72 \\
\hline & & & & 4500 & 127.31 & 111.93 & 127.71 & 109.06 & 113.02 & 107.04 \\
\hline & \multirow[t]{3}{*}{12} & & & 2500 & 130.94 & 119.16 & 131.30 & 121.87 & 120.92 & 111.92 \\
\hline & & & & 3500 & 119.51 & 106.77 & 120.40 & 106.62 & 107.57 & 103.44 \\
\hline & & & & 4500 & 103.20 & 91.05 & 104.14 & 89.29 & 91.65 & 85.14 \\
\hline & \multirow[t]{3}{*}{10} & & & 2500 & 107.13 & 100.10 & 106.75 & 102.14 & 92.60 & 95.39 \\
\hline & & & & 3500 & 97.73 & 86.63 & 98.46 & 86.97 & 85.15 & 84.55 \\
\hline & & & & 4500 & 77.78 & 69.63 & 79.06 & 70.54 & 71.38 & 67.68 \\
\hline & \multirow[t]{3}{*}{8} & & & 2500 & 82.69 & 81.18 & 83.01 & 83.03 & 74.36 & 78.19 \\
\hline & & & & 3500 & 75.29 & 67.37 & 77.14 & 68.13 & 66.42 & 66.28 \\
\hline & & & & 4500 & 57.98 & 52.45 & 59.40 & 52.33 & 53.00 & 51.05 \\
\hline
\end{tabular}

\section{Effect of web height}

The moment capacity increases as the web height increases as shown in Fig. 16. The moment capacity of the CW-180, CW-150, and CW-100 steel girders models are higher 
CW-180

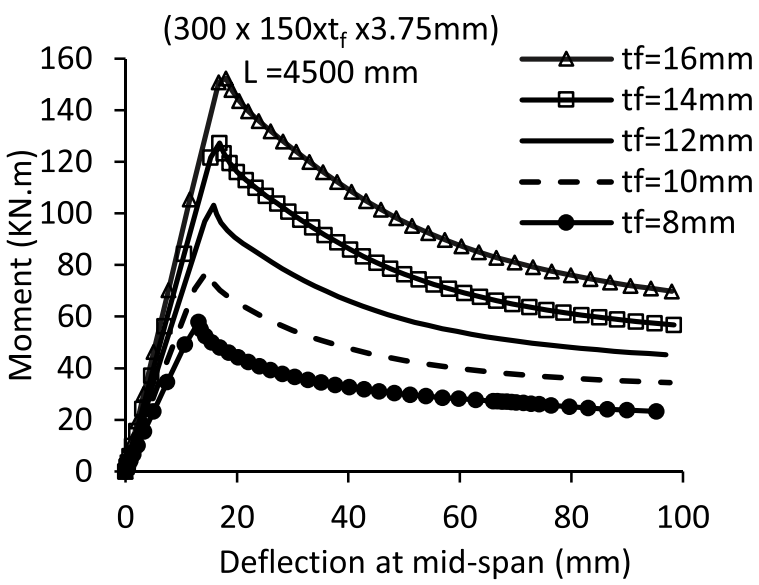

Fig. 14 Moment vs. deflection at mid-span for model CW-180 shows the effect of flange thickness $\left(t_{f}\right)$

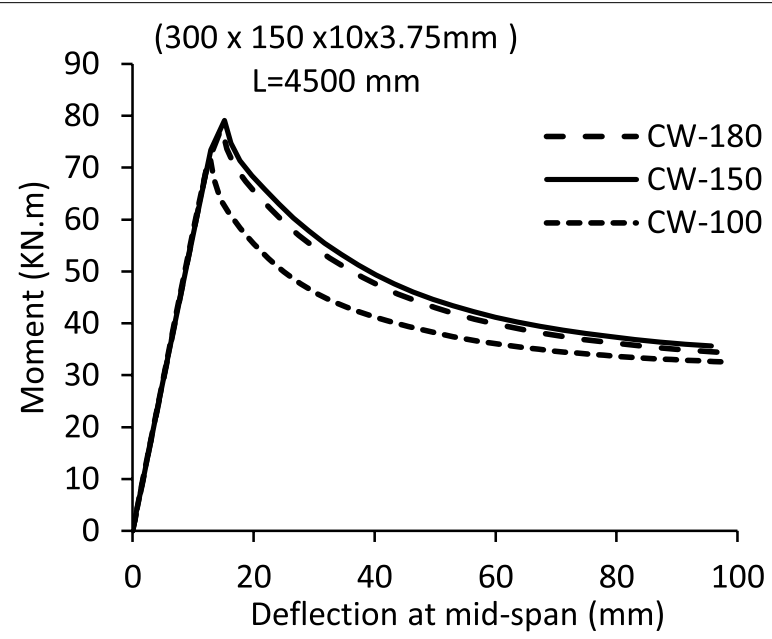

Fig. 15 Comparison between the moment capacity of CW-180, CW-150, and CW-100 models with a span of $4500 \mathrm{~mm}$

than those of the FW-180, FW-150, and FW-100 models with an average ratio of $16.04 \%$, $18.35 \%$, and $5.73 \%$, respectively. Table 6 presents the effect of using various girder depths $(H)$ on the moment capacity. The moment capacity of model CW-150 with a span of $3500 \mathrm{~mm}$ increases about $23.08 \%$ as the height of the girder increases from 240 to $360 \mathrm{~mm}$ as shown in Fig. 17. The moment capacity of model CW-150 is nearly to that of model CW-180, although it is $21.72 \%$ higher than the moment capacity of model CW-100 as shown in Fig. 18, where the girder depth taken $330 \mathrm{~mm}$ with a span of $4500 \mathrm{~mm}$.

\section{Effect of web thickness}

The moment capacity increases slightly when the web thickness increases as shown in Fig. 19. The results of varying the web thickness on the moment capacity of the girders is presented in Table 7, where $\left(t_{w}{ }^{\mathrm{ccw}}\right)$ is the corrugated web thickness and 


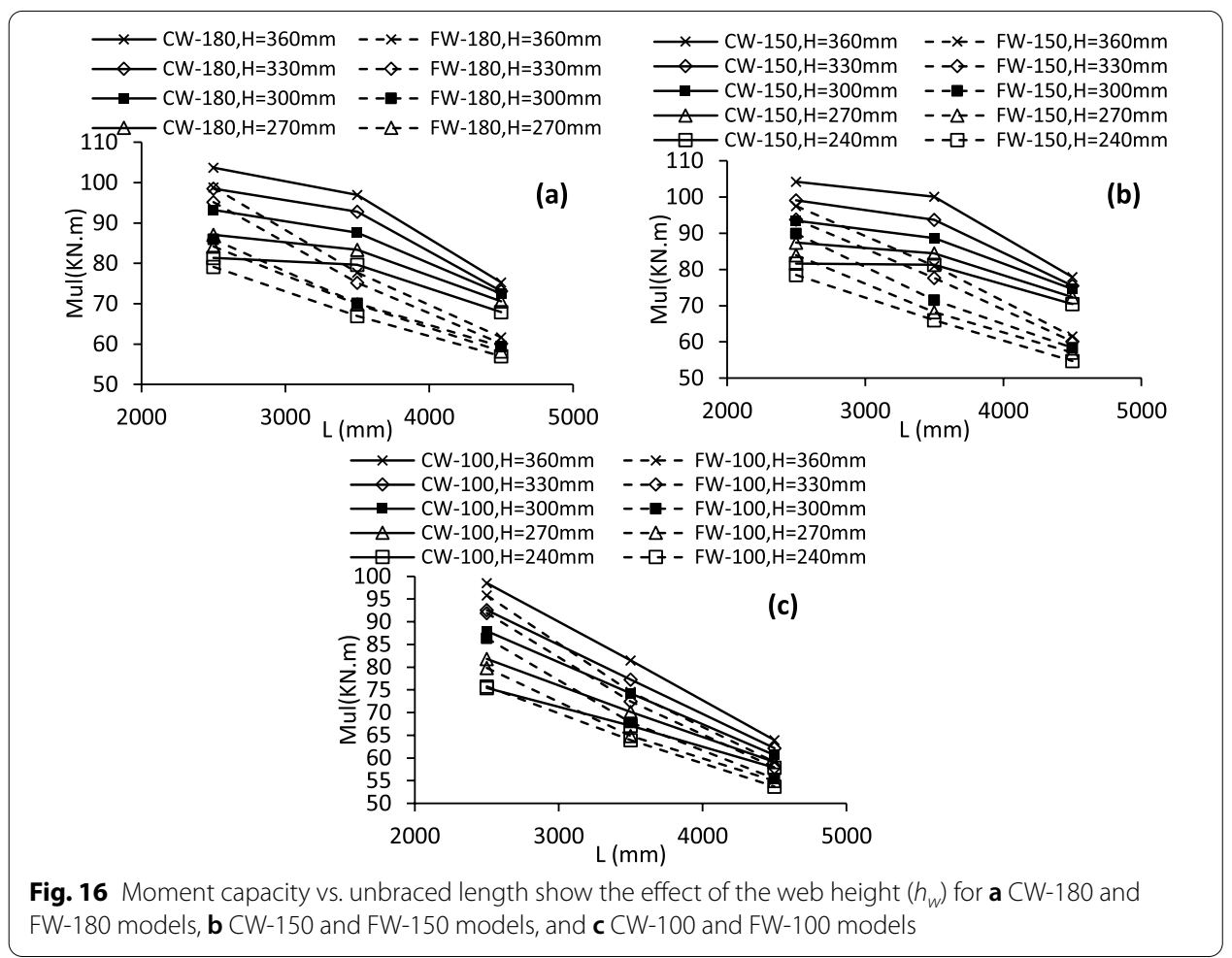

Table 6 The moment capacity using various girder depths for different spans

\begin{tabular}{|c|c|c|c|c|c|c|c|c|c|c|}
\hline \multirow{2}{*}{$\begin{array}{l}H \\
\mathrm{~mm}\end{array}$} & \multirow{2}{*}{$\begin{array}{l}t_{f} \\
\mathrm{~mm}\end{array}$} & \multirow{2}{*}{$\begin{array}{l}b_{f} \\
\mathrm{~mm}\end{array}$} & \multirow{2}{*}{$\begin{array}{l}t_{w^{\prime c w}} \\
\mathrm{~mm}\end{array}$} & \multirow{2}{*}{$\begin{array}{l}L \\
\mathrm{~mm}\end{array}$} & \multicolumn{2}{|c|}{$M_{\mathrm{ul}} \mathrm{KN} \cdot \mathrm{m}$} & \multicolumn{2}{|c|}{$M_{\mathrm{ul}} \mathrm{KN} \cdot \mathrm{m}$} & \multicolumn{2}{|l|}{$M_{\mathrm{ul}} \mathrm{KN} \cdot \mathrm{m}$} \\
\hline & & & & & CW-180 & FW-180 & CW-150 & FW-150 & CW-100 & FW-100 \\
\hline \multirow[t]{3}{*}{360} & 12 & 120 & 3.75 & 2500 & 103.72 & 98.82 & 104.20 & 97.54 & 98.54 & 95.84 \\
\hline & & & & 3500 & 96.98 & 77.76 & 100.08 & 80.98 & 81.49 & 74.56 \\
\hline & & & & 4500 & 75.29 & 61.69 & 77.94 & 61.52 & 63.91 & 59.10 \\
\hline \multirow[t]{3}{*}{330} & & & & 2500 & 98.52 & 95.19 & 99.06 & 93.80 & 92.61 & 91.90 \\
\hline & & & & 3500 & 92.83 & 75.19 & 93.73 & 77.65 & 77.27 & 72.45 \\
\hline & & & & 4500 & 73.14 & 60.15 & 75.47 & 60.09 & 62.17 & 57.94 \\
\hline \multirow[t]{3}{*}{300} & & & & 2500 & 93.28 & 85.98 & 93.47 & 89.88 & 87.99 & 86.37 \\
\hline & & & & 3500 & 87.61 & 70.09 & 88.64 & 71.57 & 74.26 & 67.80 \\
\hline & & & & 4500 & 72.45 & 59.42 & 74.57 & 58.41 & 60.60 & 55.48 \\
\hline \multirow[t]{3}{*}{270} & & & & 2500 & 87.09 & 84.16 & 87.44 & 83.97 & 81.83 & 79.85 \\
\hline & & & & 3500 & 83.34 & 69.84 & 84.47 & 68.21 & 70.16 & 64.88 \\
\hline & & & & 4500 & 70.58 & 58.23 & 72.35 & 57.07 & 59.10 & 54.95 \\
\hline \multirow[t]{3}{*}{240} & & & & 2500 & 81.36 & 79.17 & 81.58 & 78.49 & 75.41 & 75.74 \\
\hline & & & & 3500 & 79.68 & 66.93 & 81.31 & 65.99 & 67.11 & 63.91 \\
\hline & & & & 4500 & 67.94 & 57.01 & 70.47 & 54.70 & 57.84 & 53.72 \\
\hline
\end{tabular}

$\left(H / t_{w}\right)$ is the depth to web thickness ratio of the girder. The section size is considered as : $\left(300 \mathrm{~mm} \times 150 \mathrm{~mm} \times 12 \mathrm{~mm} \times \mathrm{t}_{\mathrm{w}}\right)$ using six web thickness $\left(t_{w}\right)$ with a constant girder height equals $300 \mathrm{~mm}$. The increase in the moment capacity reaches an average of $2.8 \%, 4.5 \%$, and $2.13 \%$ for the CW-180, CW-150, and CW-100 steel girders, 


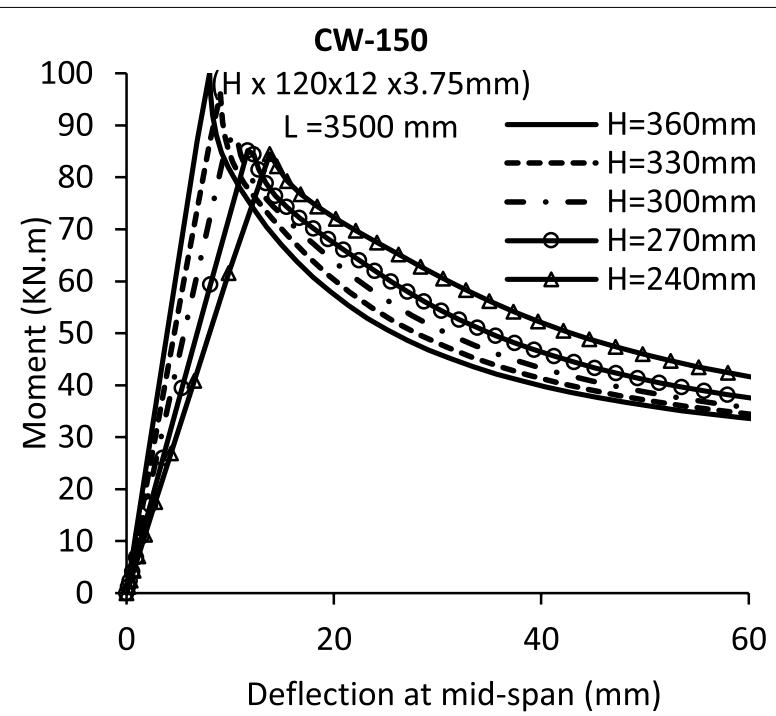

Fig. 17 Moment vs. deflection at mid-span for model (CW-150) shows the effect of web height $\left(h_{w}\right)$

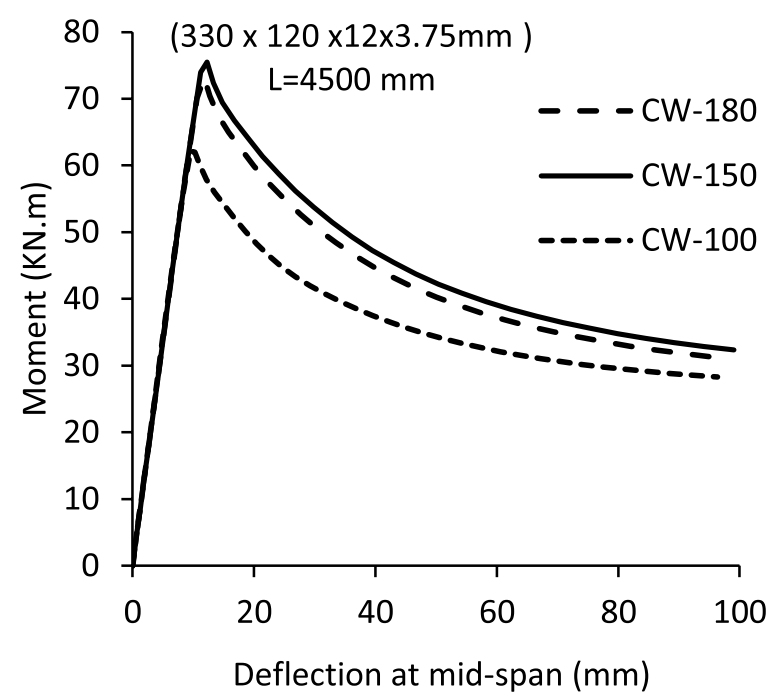

Fig. 18 Comparison between the moment capacity of CW-180, CW-150, and CW-100 models with of span of $4500 \mathrm{~mm}$

respectively when the web thickness increases from 3 to $3.75 \mathrm{~mm}$ as reducing the girder depth to web thickness ratio $\left(H / t_{w}\right)$ from 100 to 80 . When the depth to length ratio of the girder $(H / L)$ is greater than 0.12 , the local buckling of the upper flange occurs first when the girder depth to web thickness ratio $\left(H / t_{w}\right)$ is higher than 109 for corrugated web I-girders. In comparison, for equivalent flat web girders with the same depth to length ratio of the girder $(H / L)$ and the girder depth to web thickness ratio $\left(\mathrm{H} / \mathrm{t}_{\mathrm{w}}\right)$ is higher than 85.95 , the local buckling of the upper flange occurs. The figures show that the moment capacities of the corrugated web girders CW-180, CW-150, and CW-100 are higher than those of the girders with flat web FW-180, FW-150, and FW-100 with an average ratio of $14.52 \%, 14.21 \%$, and $9.92 \%$, respectively. 

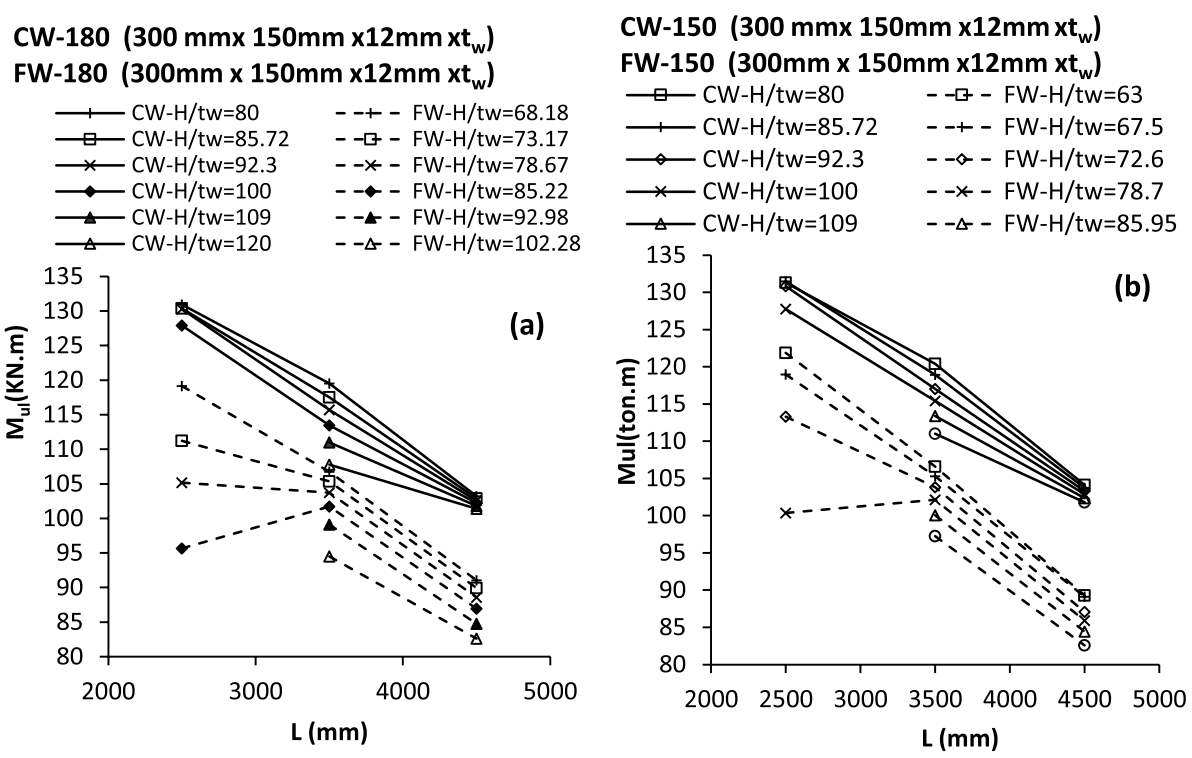

CW-100 (300 mmx 150 $\left.\mathrm{mm} \times 12 \mathrm{~mm} \times \mathrm{t}_{\mathrm{w}}\right)$ FW-100 (300mm x 150 $\left.\mathrm{mm} \times 12 \mathrm{~mm} \times \mathrm{xt}_{\mathrm{w}}\right)$

\begin{tabular}{|c|c|}
\hline$\longrightarrow-\mathrm{CW}-\mathrm{H} / \mathrm{tw}=80$ & $--\square-F W-H / t w=75$ \\
\hline$\multimap \mathrm{CW}-\mathrm{H} / \mathrm{tw}=85.72$ & - - - FW-H/tw=78.42 \\
\hline$-\mathrm{CW}-\mathrm{H} / \mathrm{tw}=92.3$ & - - $\mathrm{FW}-\mathrm{H} / \mathrm{tw}=84.5$ \\
\hline$\ldots-\mathrm{CW}-\mathrm{H} / \mathrm{tw}=100$ & $--*-F W-H / t w=91.49$ \\
\hline$\longrightarrow-\mathrm{CW}-\mathrm{H} / \mathrm{tw}=109$ & $--\mathrm{F}-\mathrm{FW}-\mathrm{H} / \mathrm{tw}=100$ \\
\hline$\triangle \mathrm{CW}-\mathrm{H} / \mathrm{tw}=120$ & $--\Delta-F W-H / t w=109.8$ \\
\hline
\end{tabular}

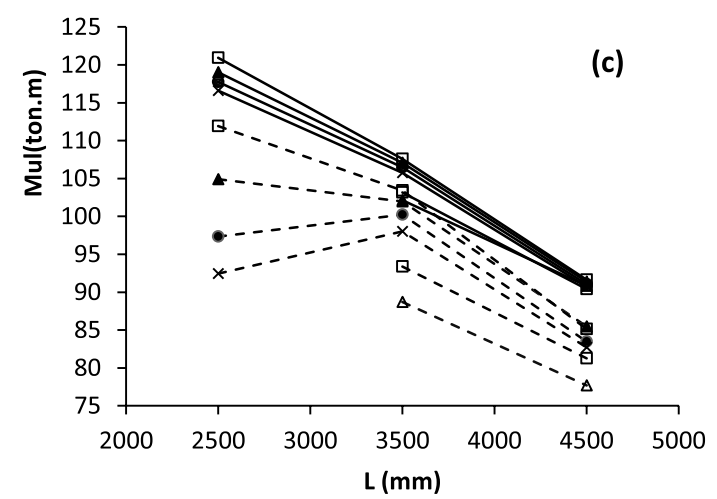

Fig. 19 Moment capacity vs. unbraced length show the effect of the web thickness $t_{w}$ for a CW-180 and FW-180 models, b CW-150 and FW-150 models, and c CW-100 and FW-100 models

\section{Effect of corrugation depth}

As observed from the previous results, the moment capacity of the corrugated web girders is influnced by the depth of the corrugation. Increasing the depth of corrugation from $20 \mathrm{~mm}$ for model CW-100 to $50 \mathrm{~mm}$ for models CW-150 and CW-180 increases the moment capacity of the corrugated web girders. While the corrugation width has a little effect on the moment capacity as found in CW-180 and CW-150, i.e.the moment capacity of CW-150 is a little higher than CW-180 for the same depth of corrugation. 
Table 7 The moment capacity using various web thicknesses for different lengths

\begin{tabular}{|c|c|c|c|c|c|c|c|c|c|c|c|}
\hline \multirow{2}{*}{$\begin{array}{l}t_{w^{\prime} \mathrm{cw}} \\
\mathrm{mm}\end{array}$} & \multicolumn{4}{|l|}{$H / t_{w}$} & \multirow{2}{*}{$\begin{array}{l}L \\
\mathrm{~mm}\end{array}$} & \multicolumn{2}{|l|}{$M_{\mathrm{ul}} \mathrm{KN} \cdot \mathrm{m}$} & \multicolumn{2}{|l|}{$M_{\mathrm{ul}} \mathrm{KN} \cdot \mathrm{m}$} & \multicolumn{2}{|l|}{$M_{\mathrm{ul}} \mathrm{KN} \cdot \mathrm{m}$} \\
\hline & CW & FW-180 & FW-150 & FW-100 & & $C W-180$ & FW-180 & CW-150 & FW-150 & CW-100 & FW-100 \\
\hline \multirow[t]{3}{*}{3.75} & 80 & 68.18 & 63 & 75 & 2500 & 130.94 & 119.16 & 131.30 & 121.87 & 120.92 & 111.92 \\
\hline & & & & & 3500 & 119.51 & 106.77 & 120.40 & 106.62 & 107.57 & 103.44 \\
\hline & & & & & 4500 & 103.20 & 91.05 & 104.14 & 89.29 & 91.65 & 85.14 \\
\hline \multirow[t]{3}{*}{3.5} & 85.72 & 73.17 & 67.5 & 78.42 & 2500 & 130.35 & 111.23 & 131.47 & 118.97 & 119.03 & 104.91 \\
\hline & & & & & 3500 & 117.51 & 105.36 & 118.94 & 105.30 & 107.07 & 101.96 \\
\hline & & & & & 4500 & 102.90 & 89.92 & 103.74 & 89.13 & 91.36 & 85.47 \\
\hline \multirow[t]{3}{*}{3.25} & 92.3 & 78.67 & 72.6 & 84.5 & 2500 & 130.28 & 105.16 & 130.83 & 113.30 & 117.73 & 97.35 \\
\hline & & & & & 3500 & 115.68 & 103.71 & 117.02 & 103.84 & 106.48 & 100.21 \\
\hline & & & & & 4500 & 102.57 & 88.59 & 103.32 & 87.09 & 91.06 & 83.47 \\
\hline \multirow[t]{3}{*}{3} & 100 & 85.22 & 78.7 & 91.49 & 2500 & 127.90 & 95.68 & 127.77 & 100.38 & 116.59 & 92.43 \\
\hline & & & & & 3500 & 113.46 & 101.72 & 115.43 & 102.14 & 105.78 & 98.01 \\
\hline & & & & & 4500 & 102.22 & 86.96 & 102.87 & 85.93 & 90.75 & 82.70 \\
\hline \multirow[t]{3}{*}{2.75} & 109 & 92.98 & 85.95 & 100 & 2500 & Local bucl & kling of up & oper flange & & & \\
\hline & & & & & 3500 & 111.01 & 99.09 & 113.38 & 100.05 & 103.15 & 93.36 \\
\hline & & & & & 4500 & 101.83 & 84.74 & 102.37 & 84.44 & 90.41 & 81.26 \\
\hline \multirow[t]{3}{*}{2.5} & 120 & 102.28 & 94.44 & 109.8 & 2500 & Local bucl & kling of up & oper flange & & & \\
\hline & & & & & 3500 & 107.78 & 94.49 & 111.00 & 97.25 & 102.13 & 88.70 \\
\hline & & & & & 4500 & 101.38 & 82.60 & 101.81 & 82.59 & 90.83 & 77.68 \\
\hline
\end{tabular}

\section{Effect of girder length}

When the length of the girder increases, the moment capacity decreases as noted from the parametric study results. The unbraced length of the compression flange affects significantly the lateral-torsional buckling behavior.

\section{Conclusions}

The lateral-torsional buckling resistance of the I-girders with circular corrugated webs under two concentrated point loads is investigated. Elastic buckling analysis is created on beams with a height of $300 \mathrm{~mm}$ and flange width range from 100 to $150 \mathrm{~mm}$ to predict buckling mode that is used for the nonlinear analysis with a suitable initial imperfection. Based on this study, the moment capacity could be increased by about $97 \%$ when the flange width increases from 100 to $150 \mathrm{~mm}$. The moment capacity can reach up to $160 \%$ when the flange thickness is increased from $8 \mathrm{~mm}$ to $16 \mathrm{~mm}$. When the depth of the girder increases from 240 to $360 \mathrm{~mm}$, the moment capacity increases about $23 \%$. The girder depth to web thickness ratio $\left(\mathrm{H} / \mathrm{t}_{\mathrm{w}}\right)$ has a slight effect on the moment capacity. However, the corrugation depth has a significant effect on the moment capacity. The moment capacity increases about 14\%, when the corrugation depth increases from 20 to $50 \mathrm{~mm}$. The unbraced length is an essential factor that affects the lateral-torsional buckling resistance. For I-girder with the same weight, the moment capacity of circular corrugated webs girder is $16 \%$ higher than that of the girder with the flat web. 
v: Poisson ratio; $f_{\text {: }}$ Yield stress; $f_{u}$ : Ultimate stress; $C W$ : Corrugated web girder; FW: Equivalent girder with flat web; $t_{w}$ : Web thickness of the I-girder with circular corrugated web; $t_{\text {equ }}$ :Web thickness of the I-girder with flat web.

\section{Acknowledgements}

Not applicable

\section{Authors' contributions}

All authors have contributed significantly to this work, have read and approved the manuscript, and agree to its submission to Journal of Engineering and Applied Science.

\section{Funding}

This study had no funding from any resource.

Availability of data and materials

All relevant data concerning the paper can be supplied by the principal investigator upon request.

\section{Declarations}

\section{Competing interests}

The authors declare that they have no competing interests.

Received: 30 December 2021 Accepted: 6 February 2022

Published online: 08 March 2022

\section{References}

1. Lindner J (1990) Lateral torsional buckling of beams with trapezoidally corrugated webs. 4th International Colloquium on Stability of Steel Structures, Budapest

2. Sayed-Ahmed EY (2005) Lateral torsion-flexure buckling of corrugated web steel girders. Struct Build 158:53-69

3. Ibrahim SA (2005) Comparative study on lateral torsional buckling of tubular plate girders using different web systems. 11th ICSGE:1-10. https://www.researchgate.net/publication/273134152_COMPARATIVE_STUDY_ON_ LATERAL_TORSIONAL_BUCKLING_OF_TUBULAR_PLATE_GIRDERS_USING_DIFFERENT_WEB_SYSTEMS

4. Chan CL, Khalid YA, Sahari BB, Hamouda AMS (2002) Finite element analysis of corrugated web beams under bending. J Constr Steel Res 58:1391-1406

5. Moon J, Yi JW, Choi BH, Lee HE (2009) Lateral-torsional buckling of I-girder with corrugated webs under uniform bending. Thin-Walled Struct 47:21-30. https://doi.org/10.1016/j.tws.2008.04.005

6. Nguyen ND, Kim SN, Han SR, Kang YJ (2010) Elastic lateral-torsional buckling strength of I-girder with trapezoidal web corrugations using a new warping constant under uniform moment. Eng Struct 32:2157-2165. https://doi. org/10.1016/j.engstruct.2010.03.018

7. Zhang Z, Li GQ, Sun FF (2010) Flexural-torsional buckling of H-beams with corrugated webs. Adv Mater Res 163-167:351-357. https://doi.org/10.4028/www.scientific.net/AMR.163-167.351

8. Larsson M (2013) Lateral-torsional buckling of steel girders with trapezoidally corrugated webs. Chalmers University of technology. Master's thesis 57:1-139. https://publications.lib.chalmers.se/records/fulltext/181187/ 181187.pdf

9. Seungjun Kim YJK (2012) Torsional and warping constants of I-shaped plate girders with a sine corrugated web. J Korean Soc Civ Eng 32:347-354. https://doi.org/10.12652/ksce.2012.32.6a.347

10. Mansour M, Ibrahim SM, Korashy M (2019) Analytical approach for lateral torsional buckling strength of triangular web profile steel beams. Int J Sci Eng Res 10:321-328

11. Eissa M (2020) Lateral torsional buckling strength of partial corrugated-web steel beams. Ain Shams Univ. https://doi.org/10.13140/RG.2.2.13314.09924/1

12. Kudryavtsev S (2019) Lateral-torsional buckling behaviour of triangularly corrugated web beam. IOP Conf Ser Mater Sci Eng 471. https://doi.org/10.1088/1757-899X/471/5/052016

13. Fatimah De'nan NSH (2013) Experimental study on bending behaviour of triangular web profile steel beam section. Int J res. Eng Technol 02:384-390. https://doi.org/10.15623/ijret.2013.0210058

14. Pimenta RJ, Queiroz G, Diniz SMC (2015) Reliability-based design recommendations for sinusoidal-web beams subjected to lateral-torsional buckling. Eng Struct 84:195-206. https://doi.org/10.1016/j.engstruct.2014.11.026

15. Jáger B, Kövesdi B, Dunai L (2019) Experimental study on the lateral-torsional buckling strength of trapezoidally corrugated web girders. Struct Stab Res Counc Annu Stab Conf SSRC 2019 2:609-622

16. Moon et al (2013) Moment gradient correction factor and inelastic flexural-torsional buckling of I-girder with corrugated steel webs. Thin-Walled Struct 62:18-27

17. Rácz AK, Jáger B, Kövesdi B, Dunai L (2018) Lateral torsional buckling resistance of Trapezoidally corrugated web girders. Int J Civ Environ Eng 12:448-453

18. Elkawas AA, Hassanein MF, Elchalakani M (2018) Lateral-torsional buckling strength and behaviour of highstrength steel corrugated web girders for bridge construction. Thin-Walled Struct 122:112-123. https://doi.org/ 10.1016/j.tws.2017.10.021

19. Hassanein MF, Elkawas AA, Shao YB et al (2020) Lateral-torsional buckling behaviour of mono-symmetric S460 corrugated web bridge girders. Thin-Walled Struct 153:106803. https://doi.org/10.1016/j.tws.2020.106803

20. Ibrahim SA, Rizkalla KB, Dessouki AK (2019) Lateral torsional buckling and strengthening techniques of coped beams with corrugated webs. Thin-Walled Struct 26212496:106533. https://doi.org/10.1016/j.tws.2019.106533 
21. Elkawas AA, Hassanein MF, El Hadidy AM et al (2021) Behaviour of corrugated web girders subjected to lateral-torsional buckling: experimental tests and numerical modelling. Structures 33:152-168. https://doi.org/10.1016/j.istruc 2021.04.057

22. Abaqus Analysis User's Manual. Version. 2019

23. 1993-3-2:2006 BE (2015) Eurocode 3: design of steel structures. Des Struct Elem 3:395-453. https://doi.org/10.1201/ b18121-19

24. ECP-205 (LRFD) (2008) Egyptian code of Practise for steel construction, Cairo

\section{Publisher's Note}

Springer Nature remains neutral with regard to jurisdictional claims in published maps and institutional affiliations.

Submit your manuscript to a SpringerOpen ${ }^{\circ}$ journal and benefit from:

- Convenient online submission

- Rigorous peer review

- Open access: articles freely available online

- High visibility within the field

Retaining the copyright to your article

Submit your next manuscript at $\boldsymbol{\Delta}$ springeropen.com 